\title{
O impacto do feminismo sobre o estudo das religiões*
}

\author{
Maria José Rosado**
}

Talvez se possa dizer que as religiões estão entre os campos que sofreram mais fortemente os impactos do feminismo, seja pelas mudanças provocadas nas práticas religiosas das mulheres, seja pela influência sobre o desenvolvimento de um novo discurso - a Teologia Feminista. Os efeitos da crítica feminista às religiões foram também dos mais contraditórios: do abandono de qualquer fé religiosa pelas mulheres, à criação de espaços feministas de espiritualidade de vários tipos, expressando uma enorme criatividade e efervescência.

$\mathrm{Na}$ área das Ciências Humanas, no entanto, o desenvolvimento de uma análise feminista das religiões que tomasse em conta as diferentes formas pelas quais as relações entre os sexos moldam práticas, representações e discursos religiosos, foi bem mais lento.

Quando, em 1985, comecei o doutorado, meu objeto de estudo era a relação mulheres e religião. Deparei-me então, com um problema de caráter teórico-metodológico. Ao buscar um quadro de análise oriundo das Ciências Sociais, que me permitisse analisar, de uma perspectiva feminista, essa complexa relação, percebi um enorme vazio, já antes observado, quando estudei as religiosas católicas. De um lado, para o feminismo laico - para nomeá-lo, de alguma maneira -, era como se, lembrando Marx, a crítica da religião já estivesse feita, o anátema lançado, e nada mais houvesse a tratar. Da parte da abordagem sociológica das

\footnotetext{
" Recebido para publicação em novembro de 2001.

** Pontifícia Universidade Católica de São Paulo.
} 
O impacto do feminismo sobre o estudo das religióes

religiões, o feminismo, enquanto proposta de análise, não existia. Parecia academicamente impróprio interrogar a realidade religiosa do ponto de vista das diferenças colocadas pelas relações sociais estabelecidas entre os sexos. Assim, abordar sociologicamente o tema religião, perguntando pelas mulheres, do ponto de vista da crítica feminista, era como andar sem bússola pelo deserto. No entanto, havia já na Europa, e mais fortemente nos Estados Unidos, uma considerável bibliografia crítica feminista elaborada por teólogas cristãs. Woodhead faz um balanço semelhante:

Até recentemente, o tópico gênero esteve quase ausente da agenda do estudo da religião. A situação mudou em parte como resultado da chamada "segunda onda" do feminismo, que se desenvolveu depois dos anos 1960. Suas perspectivas e análises, gradualmente, influenciaram muitas disciplinas que compõem o estudo da religião, da história a antropologia. ${ }^{1}$

Hoje, a situação é bastante diferente. Nas últimas décadas, não só a crítica interna estendeu-se a outras religiões nãoocidentais, como também os estudos acadêmicos feministas das religiões desenvolveram-se, para além da teologia. Já se pode encontrar um expressivo número de análises feministas da religião, em diferentes campos disciplinares: Sociologia, Antropologia, História, Psicologia, Filosofia, para nomear alguns.

No presente texto pretendo abordar esse processo de desenvolvimento de um campo próprio de estudos da religião inspirados no Feminismo, como corrente do pensamento contemporâneo. Não se trata, de forma alguma, de um trabalho exaustivo. Ao contrário, fico especialmente em dívida com a bibliografia brasileira, tanto no campo da Teologia, como no campo das Ciências Sociais e da História.

1 WoOdHEAD, Linda. REVER, Revista eletrônica de Estudos da Religião, no 4 , 2001 [no prelo]. [http://www.pucsp.br/rever/rv4_2001/t_woodhead.htm]) 
Maria José Rosado

\section{Feminismo e teologia}

Analisar o impacto do feminismo sobre os estudos de religião passa obrigatoriamente pela referência ao que aconteceu no campo da Teologia cristã, de início, e não-cristã, posteriormente. Creio ser possível afirmar que as análises feministas da religião tiveram início com o desenvolvimento de uma crítica interna à religião, feita por mulheres adeptas $e$ praticantes da fé cristã. Assim, é enquanto movimento social inspirador de práticas de resistência à situação de sujeição das mulheres que o Feminismo atua, de início, no campo religioso. Já no século XIX, surge a primeira elaboração feminista de interpretação do texto bíblico, feita por mulheres especialistas na área. Elisabeth Cady Stanton publica, entre 1895 e 1898, nos Estados Unidos, um projeto coletivo de revisão $e$ de reinterpretação da Bíblia. Esse trabalho, publicado sob o título The Woman's Bible, é considerado o ponto de partida de um longo e fragmentado processo que levará, no final dos anos 60 do século $\mathrm{XX}$, à constituição de uma Teologia Feminista, em concomitância com o surgimento da Teologia da Libertação. ${ }^{2}$

Gross, em sua obra intitulada Feminism and Religion, An Introduction, dedica um capítulo a uma "breve história" do impacto do Feminismo sobre os estudos de religião. Lembra a autora que, após algumas iniciativas no século XIX, houve um interregno de silêncio no tratamento feminista da religião, que durou até os anos 60 do século XX:

Uma grande variedade de vozes tem falado sobre feminismo e religião durante os últimos dois séculos, apesar de as vozes do século XIX $e$ as do século $\mathrm{XX}$ estarem separadas por um longo período de silêncio. (...) $\mathrm{O}$ feminismo do século XIX não se preocupou

2 Rosado NunEs, M.J.F. De mulheres e de deuses. Estudos feministas, vol. 0, $\mathrm{n}^{\circ}$ 0, CIEC/ECO/UFRG, 1992; Hunt, Mary e GiBellini, Rosino. (eds.) La sfida del femminismo alla teologia. Brescia, Queriniana, 1980. 
O impacto do feminismo sobre o estudo das religiões

\begin{abstract}
"especialmente" com a religião; apesar disso, ofereceu algumas contribuições para essa questão. Desde o final dos anos 60 , ao contrário, estudiosas feministas da religião têm desafiado e alterado consideravelmente o panorama religioso. Começando com o Judaísmo e o Cristianismo, mas agora estendendo-se a todas as religiões, clérigos/as e leigos/as feministas têm recorrido às suas tradições para levar mais a sério as vidas $e$ aspirações religiosas das mulheres. ${ }^{3}$
\end{abstract}

Nason-Clark refere os desafios postos por mulheres cristãs às suas Igrejas, "desde dentro", como um indicador, em nível amplo, "do impacto da teologia feminista sobre as religiões contemporâneas". Ela define a Teologia Feminista como fundada na promoção da igualdade das mulheres com os homens, na igreja e na sociedade. E aponta seus fundamentos no Feminismo:

Quando a segunda onda do feminismo foi introduzida no mundo ocidental, nos anos 60 a 70, mulheres teólogas começaram a incorporar sua crescente consciência feminista em sua prática religiosa e em seu trabalho acadêmico. ${ }^{4}$

$\mathrm{Na}$ década de 60, a crítica teológica feminista tem como marco, o livro de Mary Daly - The Church and the Second Sex escrito em 1968, inspirado, desde o título, pela obra clássica de Simone de Beauvoir. Sob o impacto das mudanças anunciadas pelo Concílio Vaticano II, Daly faz uma crítica contundente da Igreja Católica, para manifestar, ao final, sua esperança de uma transformação profunda das estruturas eclesiais: "A diferença fundamental entre a visão da igreja e das mulheres de Simone de Beauvoir e aquela que motivou este livro é a diferença entre o

3 Gross, Rita M. Feminism \& Religion. Boston, Beacon Press, 1996, p.29.

4 NASON-Clark, Nancy. Verbete: Feminist Theology. In: Swatos Jr., William. (ed.) Encyclopedia of Religion and Society. London, Sage, 1998, p.186. 
Maria José Rosado

desespero e a esperança". ${ }^{5}$ Alguns anos mais tarde, 1975, frustrada pelas expectativas não cumpridas após o Concílio, Daly reeditaria seu livro, com uma Feminist Postchristian Introduction A Critical review of The Church and the Second Sex, written from the perspective of 1975 A.F. (Anno Feminarum). Em 1985, uma nova edição era precedida de um New Archaic Afterwords. Ela escreve então:

A Coragem de Deixar (maiúsculas no original) uma tal instituição como a igreja Católica e, para além dela, o Cristianismo em geral e qualquer religião patriarcal, em todas as suas formas - tanto sacral quanto secular - brotou muitas vezes do desespero. ${ }^{6}$

Numa obra de 1973, que se tornou clássica para os estudos feministas do Cristianismo, Beyond God the Father, Daly faz uma afirmação inúmeras vezes repetida por feministas cristãs: "If God is male, then male is God" ["Se Deus é macho, então o macho é Deus"]. O percurso intelectual dessa autora é paradigmático, em relação ao que ocorreu com outras mulheres católicas, que passaram da proposta de mudar a instituição desde dentro ao abandono da fé cristã. Posteriormente, criaram espaços alternativos de uma espécie de "experiência espiritual coletiva feminina", razoavelmente difundida e diversificada atualmente.

Muitas outras teólogas, no entanto, continuaram a trabalhar dentro do campo das religiões institucionalizadas, cristãs ou não. Em 1983, aparece o livro de Schüssler Fiorenza em que a autora percorre o processo de patriarcalização da Igreja e da teologia cristãs. No mesmo ano, ainda no campo cristão, Ruether publica Sexism and God-Talk, Towards a Feminist Theology', apontado

${ }^{5}$ Daly, Mary. The Church and the Second Sex. New York, Harper \& Row, 1968, p.221.

6 DALY, Mary. Beyond God, the Father: Toward a Philosophyof Women's Liberation. Boston, Beacon Press, 1985, XII.

7 RuETHER, Radford. Sexism and God-Talk, Towards a Feminist Theology. 1983. 
O impacto do feminismo sobre o estudo das religióes

como um novo estágio na Teologia feminista e uma significativa contribuição para o trabalho teológico como um todo.

Nos anos 90, a diversidade de Teologias Feministas existentes é apontada em uma obra de referência: Dictionary of Feminist Theologies. ${ }^{8}$ Aí são apresentados verbetes relativos a Teologias provenientes de diferentes partes do mundo: Ásia, Europa, África, América Latina, América do Norte, Ilhas do Pacífico (!), Sul da Ásia (!). Há ainda um verbete específico para as Teologias Feministas Judaicas. As autoras do Dicionário salientam o caráter crítico dessas Teologias, apontando porém, para uma enorme variedade, tanto em relação às concepções políticas quanto às próprias concepções teóricas que embasam essa elaboração teológica.

Entre as proposições trabalhadas por esse discurso pode-se apontar as críticas manifestadas aos conteúdos tradicionais da fé: o monoteísmo, a imagem masculina da divindade, a figura submissa e virginal de Maria; as interpretações sexistas dos textos sagrados - a Bíblia, o Talmude, o Alcorão, os escritos do Budismo. Questiona-se a existência de uma só "verdade religiosa", contida em uma religião única, salvadora e portadora da redenção. Várias dessas teólogas partem de tais questionamentos, para propor uma transformação de seu próprio credo religioso, ou a criação de grupos novos, fundados sobre antigas crenças, recuperando figuras femininas de deusas, bruxas, assim como rituais considerados pagãos. Como se vê, a diversidade é enorme.

Em consonância com parte significativa de feministas, teólogas cristãs refutam ainda, a compreensão tradicional da "natureza feminina" que encerra as mulheres numa "especificidade" em que a maternidade se torna destino irrecusável. Esta rejeição do recurso à biologia para explicar o ordenamento social - e religioso - dos sexos leva-as a uma crítica

8 Russell, Letty M. \& Clarkson, J. Shannon. (eds.) Dictionary of feminist theologies. Louisville, Kentucky, Westminster John Knox Press, 1996. 
Maria José Rosado

radical da organização das instituições religiosas, apontadas como androcêntricas, hierárquicas e excludentes das mulheres. A afirmação da autonomia individual, que não se opõe à construção de ideais coletivos, mas ao contrário, a sustenta, leva-as ainda à reivindicação do reconhecimento de sua condição de agentes morais, capazes de escolhas éticas em todos os campos da vida, inclusive naqueles que relativos à sexualidade e ao controle da capacidade de conceber novos seres humanos. ${ }^{9}$

No Brasil, a elaboração teológica feminista mais difundida vem do campo cristão, protestante e católico. Tem características próprias, tanto pelo processo histórico que a engendrou, como por seu conteúdo. De qualquer forma, é também devedora do "ideário feminista 'disponível' na cultura atual". ${ }^{10}$

Finalmente, pode-se observar que a produção recente no campo teológico feminista, além de surpreender pela quantidade de obras publicadas, destaca-se ainda por haver alcançado um grau elevado de institucionalização e respeitabilidade nos meios acadêmicos. Há espaços internacionais organizados de interlocução dessas teólogas, em todos os níveis e áreas geográficas e culturais. Talvez mais do que qualquer outro campo do conhecimento, a Teologia elaborada por mulheres tenha alcançado um estatuto próprio.

\section{Estudos de religião e feminismo}

Como se verá em seguida, não é muito fácil, e talvez nem mesmo adequado, distinguir os estudos feministas de religião da

\footnotetext{
${ }^{9}$ Essa atitude crítica frente a proposições tradicionais das crenças religiosas estabelecidas conduz á indagação da construção de uma "identidade" que se afirma na dissidência. O caso católico, bastante significativo para essa questão, é estudado em livro recente de DiLlon, Michele. Catholic Identity. Cambridge, Cambridge University Press, 1999.

${ }^{10}$ RoDHEN, Fabíola. Feminismo do sagrado. Uma reencarnação romântica da diferença. Estudos Feministas, vol. 4, no 1, 1996, p.116; ROSADO NuNES, M.J.F. De mulheres e de deuses. Op. cit.
} 
O impacto do feminismo sobre o estudo das religióes

elaboração teológica feminista, dadas as inter-relações existentes entre esses dois campos de abordagem das religiões. A distinção é, no entanto, necessária, para se perceber aproximações e distinções. ${ }^{11}$

Assim como aconteceu de forma consistente na área teológica, com a constituição de um campo novo, a Teologia feminista, também nas Ciências Humanas ocorreram inovações devidas à introdução de elementos teórico-metodológicos oriundos do Feminismo, para a análise das religiões. Em um primeiro momento, a crítica das religiões foi feita no plano político $e$ militante. As religiões foram tratadas apenas como instrumentos dos mais eficazes para o controle das mulheres e a manutenção de sua subordinação social e religiosa. Woodhead considera que o legado menos útil do feminismo

foi a tendência a abordar o estudo de religião e gênero em termos de uma problemática simples: a religião é "boa" (libertadora) ou "má" para as mulheres? Ela reforça ou solapa o patriarcado?"

Posteriormente, o desenvolvimento de pesquisas de caráter acadêmico, mais analíticas e com bases empíricas, aplicaram ao domínio das religióes, conceitos e métodos de pesquisa feministas. Foi possível assim, avaliar a complexidade das relações existentes no interior do campo religioso. Desvendaram-se os laços ambíguos e contraditórios das mulheres às religiões $e$ destas às mulheres, no interior das organizações religiosas. A observação empírica mostrou as religiões como espaços sociais complexos, portadores de contradições, que não funcionam sempre e em

${ }^{11}$ Não quero, de forma alguma, identificar as abordagens da religião que partem de campos disciplinares distintos, como o são, as Ciências Sociais e a Teologia. Porém, não se pode ignorar a proximidade entre esses dois campos, particularmente, no caso dos estudos feministas de religião, dada a forma como o Feminismo influenciou a ambos.

12 WOODHEAD, L. Op.cit. 
Maria José Rosado

todas as sociedades como forças conservadoras. Dadas certas circunstâncias, elas podem funcionar como forças mobilizadoras, levando as mulheres a resistir ao seu poder disciplinador. ${ }^{13}$

Drogus analisa as mudanças ocorridas no tratamento do papel da religião na transformação social, apontando para a maneira como cientistas sociais passaram a compreender $e$ salientar "a primazia e autonomia das motivações religiosas para a ação política e a mudança social". ${ }^{14}$ Assim também, diz a autora, feministas

começaram a rever sua conclusão de que a religião contribuía inevitavelmente para a subordinação das mulheres. O movimento de espiritualidade das mulheres $e$ as teologias da libertação feministas sugeriram que as idéias religiosas retrabalhadas podiam ser mais uma fonte de empoderamento das mulheres do que de sua subordinação. Entretanto, o consenso sobre a mutabilidade das religiões e seu papel potencialmente liberador é consideravelmente menos desenvolvido. entre feministas do que entre estudantes de religião e política. Grande parte da teoria feminista ainda duvida da capacidade de um movimento iniciado em uma igreja dominada por homens emancipar as mulheres. ${ }^{15}$

$\mathrm{Na}$ avaliação de Gross, apesar do domínio histórico dos homens no campo dos estudos de religião, as estudiosas feministas foram bem sucedidas em seus esforços para estabelecer uma presença respeitada e influente.

\footnotetext{
${ }^{13}$ MACHADO, Maria das Dores C. Carismáticos e pentecostais. Adesão religiosa na esfera famliar. Campinas/São Paulo, Editores Associados/ANPOCS, 1996; ROSADO NUNES, M.J.F. De mulheres, sexo e Igreja: Uma Pesquisa e muitas interrogações. In: COSTA, Albertina e AMADO, Tina. Alternativas Escassas: Saúde, sexualidade e reprodução na América Latina. São Paulo/Rio de Janeiro, Fundação Carlos Chagas/Editora 34, 1994.

${ }^{14}$ Drogus, Carol. Women, Religion, and Social Change in Brazil's Popular Church. Notre Dame, Indiana, University of Notre Dame Press, 1997, p.6.

${ }^{15}$ ID., IB., p.6.
} 
O impacto do feminismo sobre o estudo das religióes

Assim como a prática religiosa foi transformada pelas feministas, assim também o foram os estudos acadêmicos da religião. Todas as áreas dentro dessa disciplina foram afetados pelos métodos feministas, dos estudos bíblicos ao estudo comparado das religiões. ${ }^{16}$

Levantando rapidamente a história dessa área de estudos, Gross refere o primeiro encontro de teólogas e especialistas em estudos das religiões, em junho de 1971, nos Estados Unidos. Dessa reunião saiu uma série de propostas com o objetivo de estabelecer uma agenda específica - painéis, conferências, papers - que tratasse da temática mulheres e religião, na American Academy of Religion (AAR) e na Society for Biblical Literature (SBL), duas das mais influentes associações profissionais nesse campo de estudos. Como resultado da atuação política dessas acadêmicas, uma mulher, Christine Dowing, foi eleita presidente da AAR. Estabeleceu-se uma rede de contatos entre essas acadêmicas, com efeitos positivos sobre o desenvolvimento de suas carreiras, na Teologia ou nos estudos de religião.

Ainda como resultado desses esforços, vários periódicos acadêmicos são criados, como "instrumentos críticos para o estudo feminista das religiões". ${ }^{17}$ Aparecem também as primeiras obras de maior fôlego sobre a temática em questão: Womanspirit Rising: A Feminist Reader in Religion, de Carol Christ e Judith Plaskow $^{18}$, "provavelmente o livro de maior influência e mais largamente utilizado no campo dos estudos feministas da religião". ${ }^{19}$ Em 1980, aparece Unspoken Word: Women's Religious Lives, de Nancy Auer Falk e Rita Gross. Vários outros seguem, especialmente na década de 90-2000, alargando o horizonte das

${ }^{16}$ ID., IB., p.45.

${ }^{17}$ Gross, R. M. Feminism \& Religion. Op. cit., p.49.

${ }^{18}$ CHRIST, Carol e PLASKOW, Judith. Womanspirit Rising: A Feminist Reader in

Religion. San Francisco, Harper and Row, 1979.

${ }^{19}$ Gross, R. M. Feminism \& Religion. Op. cit., p.48. 
temáticas tratadas e abrindo para o estudo comparado das religiões, incluindo as orientais, africanas, outras não institucionalizadas, do tipo Nova Era. ${ }^{20}$ No Canadá, em 1995, é publicada a coletânea multidisciplinar: Femmes et Religions, sob a direção da socióloga Denise Veillette. ${ }^{21} \mathrm{Na}$ apresentação do livro, as interrogações que o originaram: Por que a hierarquização social dos sexos? Por que a ocultação das mulheres? Por que a apropriação masculina do sagrado? Como explicar que, historicamente, um gênero, o masculino, tenha podido controlar os ritos $e$ as práticas, os discursos $e$ as crenças bem como as representações de Deus, majoritariamente, para não dizer exclusivamente?

No campo específico da Sociologia da Religião, realiza-se na França, em 1980, o Colloque de l'Association Française de Sociologie de la Religion, com a temática geral: "Oppression des femmes et Religion", cujos anais, de difícil acesso, nunca chegaram a ser publicados. O objetivo desse colóquio é definido por Danièle Hervieu-Léger:

tentar contribuir (...) para a elucidação da lógica social que preside a estruturação dessas atitudes e desses comportamentos ditos "femininos", em face da religião lógica social que a ideologia dominante - servida em primeiro lugar pelo discurso oficial das instituições religiosas - oculta et reforça imputando tais atitudes et comportamentos à ordem eterna da natureza, identificada à

\footnotetext{
${ }^{20}$ Sharma, Arvind. (ed.) Women in world religions. New York, State University os New York Press, 1987. Note-se que em 1975, Mernissi já publicara Sexe Idéologie Islam. Pesquisadora marroquina em Ciência Política e Sociologia, a autora analisa no livro as ideologias muçulmanas tradicionais e sua incidência sobre as relações homens/mulheres. MERNISSI, Fatima. Sexe idéologie islam. Paris, Tierce, 1983. (Traduzido do inglês para o francês em 1983.)

${ }^{21}$ Veillette, Denise. (dir.) Femmes et Religions. Québec, Corporation canadienne des Sciences Religieuses/Les Presses de l'Université de Laval, 1995.
} 
O impacto do feminismo sobre o estudo das religióes

vontade divina, e que define para a mulher, uma vocação específica. ${ }^{22}$

A explicação dada por Léger ao título escolhido para o colóquio - Religião e Opressão das Mulheres - é reveladora do tipo de análise proposto:

Trata-se de uma tomada de posição metodológica (sublinhado no original) que engajava a problemática deste colóquio. Poder-se-ia haver proposto "as mulheres e a religião"; não tê-lo feito era recusar a idéia de uma relação homogênea das mulheres à religião, relação que procederia de uma suposta "natureza feminina"; era excluir a hipótese de uma religiosidade feminina inscrita em alguma parte (...) na estrutura biopsíquica das mulheres; era romper com o pressuposto que toma como um fato da natureza o que nós tentamos compreender como fato social. ${ }^{23}$

Esse tipo de abordagem teórico-metodológica permitiu interrogar as religiões do ponto de vista das relações sociais entre os sexos, ou do gênero. Inúmeras pesquisas empíricas foram dedicadas a dissecar as formas pelas quais crenças, práticas $e$ representações religiosas contribuem, seja para a reprodução da desigualdade entre mulheres $e$ homens, seja para sua transformação. Em todos os campos de estudo das religiões, uma das questões fundamentais passou a ser a compreensão da maneira pela qual atividades simbólicas - crenças, ritos e discursos religiosos - que parecem escapar à diferenciação sexual, são, na verdade, moldadas por ela. A preocupação de pesquisadoras feministas tornou-se assim, mostrar como as religiões apresentam-

${ }^{22}$ LÉGER, Danièle et alii. Oppression des femmes et religion (Colloque de l'Association Française de Sociologie Religieuse). Centre d'Études Sociologiques, CNRS, Travaux et Documents, VIII Paris, 1980, p.1.

${ }^{23}$ ID., IB. 
Maria José Rosado

se, em sua realidade social e histórica, atravessadas e conformadas pelas relações de gênero.

Há, no entanto, [diz Drogus], ao menos alguma evidência sociológica que dá suporte à afirmação de que homens $e$ mulheres interpretam símbolos religiosos diferentemente.

(...) Em resumo, muitas hipóteses sugerem que o gênero é um mediador da experiência religiosa, dando peso aos estudos existentes que sugerem a importância "de desenvolver-se uma compreensão das formas pelas quais o gênero molda a experiência de ser e de tornar-se uma pessoa religiosa". ${ }^{24}$

Uma outra área de interesse são o poder institucional e os efeitos sociais e políticos da implicação religiosa das mulheres. A crítica feminista à sociologia das organizações sociais ofereceu os elementos necessários à crítica da análise das instituições religiosas. Estudiosas das religiões mostraram a inadequação de se tratar as categorias utilizadas como supostamente neutras em termos de gênero. Tal tratamento impede a percepção de elementos fundamentais para a análise da realidade das religiões. No campo católico, por exemplo, o uso genérico de categorias como clero, hierarquia, sem referência ao fato de que se referem a um grupo exclusivamente masculino impede a análise das relações de poder que presidem a organização dessa instituição religiosa. Woodhead salienta que foi a falta de atenção ao gender factor o que impediu cientistas da religião de compreenderem a ressurgência da religião, após o anúncio de seu declínio, pelas teorias da secularização:

Uma das razões pelas quais o largo ressurgimento das religiões no final do século XX pegou tantos sociólogos $e$ comentaristas de surpresa, e abalou tantas teorias da

${ }^{24}$ Davidman and Greil apud Drogus, Carol. Women, Religion, and Social Change... Op. cit., pp.11-12. 
O impacto do feminismo sobre o estudo das religióes

secularização foi sua falha em prestar suficiente atenção ao "fator gênero". ${ }^{25}$

Além dos estudos empíricos, pesquisadoras feministas dedicaram-se ainda, à crítica teórica, analisando autores clássicos da Sociologia da Religião. Bologh e Erickson ${ }^{26}$ apontam para o caráter sexista inerente ao pensamento deles e que contamina sua análise da religião. A rígida divisão entre sagrado e profano, na obra de Durkheim, apresentada como constitutiva das religiões e da sociedade, acaba por relegar as mulheres ao domínio profano/privado. Apenas os homens são portadores do sagrado, protagonistas de crenças $e$ ritos pelos quais novas relações $e$ a própria sociedade são criadas. Já Max Weber associa os homens às religiões fundadas sobre $\mathrm{o}$ ascetismo racional que permite $\mathrm{o}$ surgimento da figura do líder, do herói. Às mulheres restam as religiões mágicas, que incorporam o erotismo e afastam da "ação no mundo". Resultado: homens ativos, mulheres passivas, tanto na religião como na sociedade.

De um ponto de vista estritamente sociológico, Woodhead propõe uma "teoria geral" para o estudo de religião e gênero. Segundo ela, o envolvimento das mulheres com a religião

tem menos a ver com "falsa consciência" do que com as formas pelas quais as religiões oferecem espaços sociais para a articulação e, em alguns casos, para a realização dos desejos das mulheres. ${ }^{27}$

\footnotetext{
${ }^{25}$ WOODHEAD, L. Op. cit.

${ }^{26}$ Bologh, Roslyn W. Love or Greatness, Max Weber and masculine thinking - A Feminist Inquiry. London, Unwin Hyman, 1990; e ERICKSON, Victoria Lee. Where Silence Speaks. Feminism, Social Theory and Religion. Minneapolis, Fortress Press, 1993.

${ }^{27}$ REVER, Revista eletrônica de Estudos da Religião, $\mathrm{n}^{\circ}$ 4, 2001.

[http://www.pucsp.br/rever/rv4_2001/t_woodhead.htm])
} 
Maria José Rosado

Ela explica que esta afirmação não nega que desejos não são "naturais", mas modelados pelo contexto social do qual as religiões são parte. Ou que essa função pode ser cumprida por outros espaços sociais, e não pela religião. Ou ainda, "para que as religiões se tornem espaços nos quais as mulheres possam articular suas vidas e seus desejos, elas devem subvertê-las, apropriar-se delas ou reinterpretá-las". Assim, para Woodhead, o grau de participação, ou a falta de participação das mulheres nas religiões é dada pela disponibilidade ou não de espaços sociais que permitam a articulação de seus desejos, de seus medos, de suas vidas. A relação das religiões com a crescente diferenciação social das sociedades modernas e a conseqüente separação das esferas pública e privada será então o elemento explicativo do papel das religiões para as mulheres. Tomando em consideração as sociedades ocidentais altamente diferenciadas, de um lado, $e$ as sociedades diferenciadas não-ocidentais, de outro, Woodhead propõe três quadros diferentes:

a) Em sociedades menos diferenciadas, as religiões são parte do processo modernizador e, em muitos casos, as mulheres usam-nas como facilitadoras do processo de entrada em novos espaços sociais, sem $\mathrm{O}$ abandono das responsabilidades domésticas. É ocaso das CEBs e dos grupos pentecostais no Brasil.

b) Em sociedades mais industrializadas, com avançado processo de diferenciação das esferas, a religião é impulsionada para a esfera privada e identificada com os valores da família e a preservação do espaço doméstico. A relação das mulheres com a religião torna-se, então, conflitiva, uma vez que elas, as mulheres, estão em um processo de entrada na vida pública, assumindo uma vida profissional. Valores religiosos e valores seculares chocam-se nesse contexto. As mulheres podem, em conseqüencia, abandonar as religiões tradicionais. No entanto, pode acontecer também o contrário: A diferenciação extrema entre valores seculares e religiosos pode reforçar a participação religiosa das mulheres, oferecendo-lhes, no caso de sua exclusão do espaço 
O impacto do feminismo sobre o estudo das religióes

público, um outro lugar valorizado pela religião - o espaço doméstico - possibilitando-lhes sentirem-se confortáveis.

c) Nas sociedades pós-industriais, em que a separação público/privado é relativizada, estimulando o empoderamento individual $e$ a relacionalidade, "os valores das mulheres, suas maneiras de trabalhar e de relacionar-se ganham nova relevância "pública e valor econômico". A religião pode então ser revitalizada, tanto em sociedades ocidentais como em nãoocidentais.

Woodhead, referindo várias pesquisas empíricas sobre diferentes religiões em diversos tipos de sociedade, vê em algumas delas, formas religiosas de feminismo, o que, do meu ponto de vista, pode ser bastante discutível. Outra de suas conclusões, mais plausível, me parece, é que

as religiões que sobreviverão $e$ florescerão em um novo milênio serão aquelas que tiverem mais sucesso em atrair as mulheres e prover espaços sociais para a articulação dos seus medos e desejos, em um mundo em rápida mutação. As repercussões sociais e políticas do seu sucesso serão também significativas [Mulheres muçulmanas, por exemplo, constituem atualmente, um décimo da humanidade.$^{28}$

Além da Sociologia, uma outra área em que as contribuições feministas têm sido significativas, é a da História das religiões. Fazendo um estado da questão das Ciências Religiosas feministas, Lacelle coloca as historiadoras entre "as primeiras a tomar consciência da memória seletiva e sexuada das construções históricas". ${ }^{29}$ Interrogando a historiografia existente, o silêncio sobre o protagonismo feminino e enfrentando a dificuldade das fontes, historiadoras das religiões têm buscado escrever uma outra história, em que fatos, personagens, processos são moldados pelas

${ }^{28}$ WOODHEAD, L. Op. cit.

${ }^{29}$ LACELLE, Élisabeth J. Les Sciences Religieuses Féministes: Un État de la Question. In: VeilletTe, Denise. (dir.) Femmes et Religions. Op. cit., p.61. 
Maria José Rosado

relações estabelecidas entre os sexos. ${ }^{30}$ Também as religiosas católicas, "rigorosamente treinadas para não terem história pessoal ou comunitária", têm sido objeto de pesquisa histórica $e$ sociológica. ${ }^{31} \mathrm{Em}$ texto intitulado: "Gênero como Categoria de Análise na História das Religiões", Bidegain conclui:

(...) a incorporação da categoria de gênero, cruzada com as de classe social e etnia, não só é útil para a elaboração da história das religiões, é também uma chave essencial para a compreensão da história invisível das mulheres nas religiões e suas relações com todas as formas de estruturação do poder. $^{32}$

\section{Para concluir}

O objetivo deste texto foi o de levantar a influência das idéias feministas sobre os estudos da religião. Optei pela tentativa de reconstruir o percurso dos estudos feministas das religiões, percorrendo, de maneira não sistemática, a bibliografia existente

\footnotetext{
${ }^{30}$ SalisburY, Joyce E. Padres de la Iglesia, Vírgenes Independientes. Bogotá, TM Editores, 1994; VALERIO, Adriana. La questione femminile nei secoli X - XII. Napoli, M. D’Auria editore in Napoli, 1983; LAVRIN, Asunción. (ed.) Latin American Women. Historical perspectives. Westport, Connecticut, Greenwood Press, 1978; DuBY, George e PERROT, Michelle. História das mulheres no ocidente. Porto/São Paulo, Afrontamento, vols. 1-5, 1990.

${ }^{31}$ Algranti, Leila Mezan. Honradas e devotas: mulheres da colônia. Condição feminina nos conventos e recolhimentos do Sudeste do Brasil, 1950-1822. Rio de Janeiro, José Olympio e Brasília, Edunb, 1993; MCNAMARA, Jo Ann Kay. Sisters in Arms. Cambridge. Harvard University Press, 1996; RosAdo NunES, M.J.F. Freiras no Brasil. In: Del PRIORE, Mary. (org.) História das mulheres no Brasil. São Paulo, Contexto, 1997. Nos últimos anos, o estudo das freiras, restrito quase exclusivamente, no caso do Brasil, à teologia, tem sido objeto de algumas dissertações e teses no campo das Ciências Sociais.

32 Bidegain, Ana Maria. Gênero como Categoria de Análise na História das Religiões. In: BidEGAIN, A. M. (org.) Mulheres: Autonomia e Controle Religioso na América latina. São Paulo/Petrópolis, Vozes/CEHILA, 1996, p.28.
} 
O impacto do feminismo sobre o estudo das religióes

em alguns dos campos disciplinares que têm a religião como seu objeto. Dados os limites de espaço e por não se tratar de estudo exaustivo, a escolha de áreas e da bibliografia referida acabou sendo limitada. Intercalando a seqüência histórica com observações relativas ao conteúdo temático, o texto traçou um panorama que permite avaliar a força das idéias feministas nesse campo. ${ }^{33}$

Pode-se dizer, ao final, que entre as principais preocupações críticas dessas abordagens está o questionamento das possibilidades reais de mudanças favoráveis ás mulheres, no campo das religiões históricas. Para algumas pesquisadoras e para um certo número de teólogas, o androcentrismo é parte inerente das religiões. O investimento da população feminina nessas religiões é a expressão de seu conservadorismo. Elas propõem a criação de espaços religiosos alternativos, onde as mulheres possam fazer emergir novas formas de relação com o sagrado, também este pensado de maneira inovadora. Para outras, o problema das religióes históricas foi a sua apropriação pelos homens. Um dos objetivos das pesquisas a serem feitas deverá ser o de recuperar as tradições e os fundamentos das mesmas, para que as mulheres encontrem aí o seu lugar.

\footnotetext{
${ }^{33}$ Em um próximo estudo, como parte de uma pesquisa de pós-doutorado que venho desenvolvendo, pretendo sistematizar as áreas temáticas atingidas pelas idéias feministas e as questões teórico-metodológicas colocadas pelas pesquisas feministas que abordam as relações das mulheres às religiões, analisando, particularmente a bibliografia brasileira.
} 